\title{
Association between obesity and Barrett's esophagus in a Japanese population: a hospital-based, cross-sectional study
}

\author{
Jiro Watari, Kazutoshi Hori, Fumihiko Toyoshima, Noriko Kamiya, Takahisa Yamasaki, Takuya Okugawa, \\ Haruki Asano, Zhao Liang Li, Takashi Kondo, Hisatomo Ikehara, Jun Sakurai, Toshihiko Tomita, Tadayuki Oshima, \\ Hirokazu Fukui and Hiroto Miwa
}

\begin{abstract}
Background: The association between obesity and Barrett's esophagus (BE) in the Japanese population remains unclear. The prevalence of BE and its associated risk factors was examined.

Methods: A cross-sectional study of 1581 consecutive individuals who underwent upper gastrointestinal endoscopy was conducted. The prevalence of endoscopically suspected BE (ESBE) was evaluated. Obesity was evaluated by body mass index (BMl, $\geq 25 \mathrm{~kg} / \mathrm{m}^{2}$ ) and waist circumference (WC) (males, $\geq 85 \mathrm{~cm}$; females, $\geq 90 \mathrm{~cm}$ ). Because endoscopic diagnosis of ultra-short ESBE $(<1 \mathrm{~cm}$ in extent) is difficult and highly unreliable, this type of ESBE was excluded from the study.

Results: In proton pump inhibitor (PPI) non-users, the prevalence of ESBE $\geq 1 \mathrm{~cm}$ was $5.6 \%$. In univariate analysis, male sex and reflux esophagitis (RE) were significantly associated with $B E$, but $B M I, W C$, and reflux symptoms were not. In multivariate logistic regression analysis, only RE (odds ratio $[\mathrm{OR}]=3.48,95 \%$ confidence interval $[\mathrm{CI}] 1.89-6.41, \mathrm{p}<0.0001$ ) was an independent risk factor for BE; obesity and the other factors were not. In contrast, RE (OR 5.67, $\mathrm{P}=0.0004)$ and large WC (OR 5.09, $p=0.0005$ ) were significant risk factors for ESBE $\geq 1 \mathrm{~cm}$ in PPI users. Only male sex, but not obesity or the other risk factors, was associated with an increased risk of RE in patients not taking PPIs.
\end{abstract}

Conclusions: RE, but not obesity, may have an independent association with the risk of ESBE in the Japanese population. Furthermore, obesity measures were not independent risks for RE. Interestingly, PPI-refractory RE and large WC were risk factors for ESBE $\geq 1 \mathrm{~cm}$ in patients taking PPIs.

Keywords: Barrett's esophagus, Body mass index, Waist circumference, Visceral obesity, Reflux esophagitis

\section{Background}

The main risk for Barrett's esophagus (BE) is considered to be gastroesophageal reflux disease (GERD) [1-4]. ElSerag reported that the incidence GERD has increased significantly in each of the last two decades in North America and Europe but not Asia [5]. However, the incidence of GERD is increasing in Japan as well as in the West [6]. These results suggest that the prevalence of GERD-associated BE will increase in Japan over the next few decades.

\footnotetext{
* Correspondence: watarij@hyo-med.ac.jp

Division of Upper Gastroenterology, Department of Internal Medicine, Hyogo College of Medicine, 1-1, Mukogawa-cho, Nishinomiya 663-8501, Japan
}

There is strong evidence from epidemiological studies conducted among Western populations that total obesity, as measured by body mass index (BMI), is associated with GERD symptoms, reflux esophagitis (RE) and esophageal adenocarcinoma $[7,8]$. Furthermore, these studies have shown that waist circumference (WC) and the waist-to -hip ratio (WHR), both of which measure abdominal fat, are risk factors for $\mathrm{BE}$, independent of BMI $[9,10]$.

In contrast, few studies have investigated the association between obesity and BE in a Japanese population. $\mathrm{RE}$ studies conducted in Japan have found a positive association between high BMI and RE [11,12], and RE is thought to be associated with the development of $\mathrm{BE}$ in the Japanese population $[13,14]$. In their retrospective

\section{Ciomed Central}


study, Akiyama et al. reported a positive association between visceral obesity and BE in Japanese patients with non-alcoholic fatty liver disease, with visceral obesity being defined using visceral adipose tissue (VAT) measurements on abdominal computed tomographic images, but the strength of the risk of $\mathrm{BE}$ was very weak (odds ratio [OR], 1.0074; 95\% confidence interval [CI], 1.00011.0147, $\mathrm{p}=0.0472$ ) [15]. Previous reports from Japan on the association between obesity and RE or BE have been limited to retrospective studies $[13,15]$. Therefore, it remains controversial whether obesity is actually an independent risk factor for BE in Japanese subjects.

In most of the BE cases identified in Japan, the lesions were very short, i.e., $<1 \mathrm{~cm}$ in length. Such cases are classified as ultra-short $\mathrm{BE}$, although the diagnosis of this disease entity is difficult and highly unreliable [16-18]. One possible reason for the difficulty may be the use of different definitions of the gastroesophageal junction (GEJ), i.e., the distal end of the esophageal palisade vessels versus the proximal margin of the gastric folds $[16,19,20]$. As defined in the West, BE diagnosis requires histological confirmation of the specialized intestinal metaplasia (SIM). Thus, cases without histological confirmation of SIM are defined as endoscopically suspected BE (ESBE) in the US but are not regarded as BE [21]. Furthermore, the previous studies have included patients who were taking proton pump inhibitors (PPIs), which may induce the regression and normalization of BE $[14,22,23]$. Thus, the associations between obesity and BE should be investigated separately in patients taking and those not taking PPIs.

A recent study by Kramer et al. found no associations between BMI, WHR and short-segment BE, but a strong and statistically significant association between WHR and long-segment BE in the US [24]. In the current study, we focused on short-segment BE, and excluded ultra-short BE, and analyzed the association between this disease entity and obesity separately in patients taking and those not taking PPIs in Japan.

\section{Methods}

\section{Patients}

A hospital/clinic-based, cross-sectional, pilot study assessing the association between obesity and the development of BE was performed. Between November 2011 and June 2012, 1581 consecutive patients who underwent upper endoscopy at the Gastroenterology Division of Hyogo College of Medicine Hospital $(\mathrm{n}=1114)$, one affiliated hospital $(n=327)$, and one clinic $(n=140)$ were enrolled in this study. Most patients were outpatients, and patients who had previously undergone upper gastrointestinal tract surgery, who had previously undergone endoscopy during this period, and those who were followed in the surveillance registry of $\mathrm{BE}$ in our department were excluded. At the affiliated hospital and the clinic, transnasal endoscopy with an ultrathin endoscope was performed only for medical check-up, while at our college hospital endoscopy was performed for various reasons, such as GERD symptoms ( $n=200,18.0 \%)$, detailed examination of gastric cancer or neoplasms ( $\mathrm{n}=78,7.0 \%)$, follow-up study after endoscopic treatment for dysplasia and/or cancer $(n=36,3.2 \%)$, and other reasons, including screening, follow-up for peptic ulcers, and so on. A standardized questionnaire was used to obtain a history from each subject regarding GERD symptoms, smoking and alcohol habits prior to endoscopy. Whether or not subjects were taking PPIs was determined by self-report and a review of the medical prescriptions in our database. The Ethics Committee of Hyogo College of Medicine and the affiliated hospital and clinic approved this study. Written, informed consent was obtained from all patients prior to this study.

\section{Endoscopy protocol}

In Japan, the GEJ is defined as the distal limit of the lower esophageal palisade vessels [21], but in the West the GEJ is defined as the proximal margin or upper end of the gastric folds (Prague C\&M criteria) [16]. In the present study, ESBE was diagnosed endoscopically as columnar-lined epithelium between the lower end of the palisade vessels of the lower esophagus and the squamocolumnar junction. However, if the palisade vessels could not be visualized clearly, the upper end of the gastric folds was regarded as the GEJ. When the ESBE length was considered to be $1 \mathrm{~cm}$ or more, the length was measured in comparison to the length of the endoscope. In contrast, when the length was considered to be $<1.0 \mathrm{~cm}$, the ESBE length was judged in comparison to the biopsy forceps (the open forceps were about $7 \mathrm{~mm}$ in diameter; Radial Jaw ${ }^{\mathrm{Tm}}$ 4: Boston Scientific Corporation, Natick, MA). If possible, at least one biopsy specimen was obtained from ESBE, > $5 \mathrm{~mm}$ in extent, in order to confirm the presence of SIM on histology. Atrophic gastritis was classified into 2 types according to the Kimura and Takemoto classification [25]: the closed type, as mild atrophic gastritis (C 1-3), and the open type, as severe atrophic gastritis (O 1-3). RE was diagnosed based on the Los Angeles (LA) classification [26], and individuals with LA classification grade A or more were considered positive for RE. These endoscopic data were prospectively collected.

\section{Measures of adiposity}

Prior to endoscopy, we performed the following body measurements of the subjects. BMI was calculated as weight divided by the square of height $\left(\mathrm{kg} / \mathrm{m}^{2}\right)$. "Obesity" was defined as BMI $\geq 25.0 \mathrm{~kg} / \mathrm{m}^{2}$, based on the criteria of the Japanese Society of Obesity [27]. A large WC based on the Japanese criteria $(\geq 85 \mathrm{~cm}$ for men, $\geq$ $90 \mathrm{~cm}$ for women) was defined as an abnormal WC [28]. 
The high-risk category for WHR was defined as $\geq 0.9$ for males and $\geq 0.85$ for females, according to the definition of Ilanne-Parikka et al. [29].

\section{Symptoms and habits}

GERD symptoms were defined as the presence of either heartburn or acid regurgitation at least once weekly. Also, the presence of a current alcohol (active consumption of any amount of alcohol) or cigarette (active smoking of any number of cigarettes) habit was determined by interview prior to the study. A PPI user was regarded as a patient who had continuously taken a PPI such as omeprazole (20 mg/day), lansoprazole (15 or $30 \mathrm{mg} /$ day), rabeprazole (10 or $20 \mathrm{mg} /$ day), or esomeprazole (20 mg/day) once a day beginning at least 2 months before this study.

\section{Statistical analysis}

The data were assessed by the Mann-Whitney $U$-test for patients' age and adiposity measures, and the chisquare test or Fisher's exact test for the other variables between the two groups. Statistical significance was defined as a $p$ value $<0.05$. Odds ratios (ORs) and the corresponding 95\% confidence intervals (CIs) for risk factors for ESBE and RE were calculated using StatView Version 5.0 for Macintosh (SAS Institute Inc., Cary, $\mathrm{NC}$ ). We included all factors with $\mathrm{p}<0.10$ in unadjusted models in the multiple logistic regression model. Those factors with $\mathrm{p}>0.05$ in backwards stepwise regression were dropped from the final model.

\section{Results}

\section{Patient characteristics}

A total of 1581 individuals (921 men, 660 women) were enrolled in this study. Their mean age was $58.9 \pm$ 14.7 years (range: 18 to 92 years). Of these, 1214 patients
(76.8\%) were not taking PPIs and, of these, 840 (69.2\%) showed no evidence of ESBE on endoscopy and thus constituted our control group. On the other hand, the remaining 367 patients were regular PPI users, of whom 256 (69.8\%) did not show ESBE and the remaining 111 (30.2\%) had ESBE.

Among patients who were not taking PPIs $(n=1214)$, the prevalence of ESBE was 30.8\% (374 cases): $25.2 \%$ ( $\mathrm{n}=$ 306) for ultra-short ESBE, $5.4 \%(n=65)$ for ESBE of $\geq 1 \mathrm{~cm}$ but $<3 \mathrm{~cm}$, and only $0.2 \%(\mathrm{n}=3)$ for long-segment ESBE (LSBE, ESBE $\geq 3 \mathrm{~cm}$ ). On the other hand, that of ESBE among patients taking PPIs (367 cases) was 30.3\%: 24.0\% $(\mathrm{n}=88)$ for ultra-short-segment ESBE, 5.2\% $(\mathrm{n}=19)$ for ESBE of $\geq 1 \mathrm{~cm}$ but $<3 \mathrm{~cm}$, and $1.1 \%(\mathrm{n}=4)$ for longsegment ESBE.

\section{Factors predicting development of ESBE $\geq 1 \mathrm{~cm}$ and RE}

Because endoscopic diagnosis of ultra-short ESBE is difficult and highly unreliable, as mentioned above, patients with ultra-short ESBE were excluded from this evaluation.

As shown in Table 1, SIM was identified in patients with $E S B E \geq 1 \mathrm{~cm}$ (38.8\%) among PPI non-users in whom a biopsy could be obtained, but did not differ from the frequency of SIM (44.4\%) among regular PPI users who underwent biopsy. In patients not taking PPIs, there was no significant difference in age between the controls and the ESBE group. The percentage of males was significantly higher among patients with ESBE $\geq$ $1 \mathrm{~cm}$ than among controls $(\mathrm{p}=0.03)$. RE was detected with significantly greater frequency in patients with ESBE $\geq 1 \mathrm{~cm}$ than among controls $(\mathrm{p}<0.0001)$, both for patients taking and those not taking PPIs.

Among both patients taking and those not taking PPIs, all adiposity measures including BMI, WC, and WHR in

Table 1 Clinical characteristics of the patients with endoscopically suspected Barrett's esophagus $\geq 1 \mathrm{~cm}$

\begin{tabular}{|c|c|c|c|c|c|c|}
\hline & \multicolumn{3}{|c|}{ PPI non-users } & \multicolumn{3}{|c|}{ PPI users } \\
\hline & Controls & $\mathrm{ESBE} \geq 1 \mathrm{~cm}$ & $P$ & Controls & $\mathrm{ESBE} \geq 1 \mathrm{~cm}$ & $P$ \\
\hline Number & $840(69.2)$ & $68(5.6)$ & - & $256(69.8)$ & $23(6.3)$ & - \\
\hline SIM & - & 19/49 (38.8) & - & - & 8/18 (44.4) & - \\
\hline \multicolumn{7}{|l|}{ Patients profile } \\
\hline Age, y & $56.2 \pm 14.8$ & $58.3 \pm 13.6$ & 0.31 & $63.5 \pm 15.3$ & $67.5 \pm 12.4$ & 0.26 \\
\hline Male sex & $464(55.2)$ & $47(69.1)$ & 0.03 & $129(50.4)$ & $14(60.9)$ & 0.34 \\
\hline Alcohol drinking & $244(29.0)$ & $20(29.4)$ & 0.95 & $54(21.1)$ & $8(34.8)$ & 0.13 \\
\hline Current smoking & $173(20.6)$ & $14(20.6)$ & 0.99 & $34(13.3)$ & $3(13.0)$ & $>0.99$ \\
\hline GERD symptoms & $126(15.0)$ & $12(17.6)$ & 0.56 & $74(28.9)$ & $9(39.1)$ & 0.30 \\
\hline \multicolumn{7}{|l|}{ Endoscopic findings } \\
\hline Reflux esophagitis & $68(8.1)$ & $17(25.0)$ & $<0.0001$ & $22(8.6)$ & $8(34.8)$ & 0.0001 \\
\hline Gastric atrophy (Open-type) & $158(18.8)$ & $16(23.5)$ & 0.34 & $96(37.5)$ & $6(26.1)$ & 0.28 \\
\hline
\end{tabular}


Table 2 Distributions of BMI, WC and WHR among cases and controls

\begin{tabular}{|c|c|c|c|c|c|}
\hline \multicolumn{6}{|c|}{ A. Patients not taking PPIs } \\
\hline Adiposity measures & Controls & (\%) & $\mathrm{ESBE} \geq 1 \mathrm{~cm}$ & (\%) & $P$ value \\
\hline $\mathrm{BMI}, \mathrm{kg} / \mathrm{m}^{2}$ & $21.8 \pm 3.5$ & $(17.2)^{*}$ & $22.9 \pm 2.64$ & $(30.4)^{*}$ & 0.11 \\
\hline WC, cm & $80.3 \pm 10.8$ & $(23.4)^{* *}$ & $82.7 \pm 8.68$ & $(60.9)^{* *}$ & $<0.0001$ \\
\hline WHR & $0.87 \pm 0.08$ & $(49.6)^{\dagger}$ & $0.90 \pm 0.04$ & $(42.9)^{\dagger}$ & 0.55 \\
\hline \multicolumn{6}{|c|}{ B. Patients regularly taking PPIs } \\
\hline Adiposity measures & Controls & $(\%)$ & $\mathrm{ESBE} \geq 1 \mathrm{~cm}$ & (\%) & $P$ value \\
\hline $\mathrm{BMI}, \mathrm{kg} / \mathrm{m}^{2}$ & $22.4 \pm 3.5$ & $(19.5)^{*}$ & $22.3 \pm 3.3$ & $(19.1)^{*}$ & 0.94 \\
\hline$W C, \mathrm{~cm}$ & $80.8 \pm 10.2$ & $(29.8)^{* *}$ & $81.5 \pm 10.1$ & $(36.8)^{* *}$ & 0.27 \\
\hline WHR & $0.88 \pm 0.08$ & $(46.7)^{\dagger}$ & $0.88 \pm 0.06$ & $(42.3)^{\dagger}$ & 0.54 \\
\hline
\end{tabular}

$B M I$ body mass index, WC waist circumference, WHR waist-to-hip ratio, PPI proton pump inhibitor. ESBE endoscopically suspected Barrett's esophagus.

$P$ values indicate the comparison in the prevalence between controls and ESBE $\geq 1 \mathrm{~cm}$.

* The prevalence indicates body mass index $\geq 25 \mathrm{~kg} / \mathrm{m}^{2}$.

** The prevalence indicates a large waist circumference defined as $\geq 85 \mathrm{~cm}$ for males and $\geq 90 \mathrm{~cm}$ for females.

† The prevalence indicates a large waist-to-hip ratio defined as $\geq 0.9$ for males and $\geq 0.85$ for females.

patients with $E S B E \geq 1 \mathrm{~cm}$ were not significantly different from those among controls (Table 2). However, the prevalence of large WC was significantly higher in patients with $B E \geq 1 \mathrm{~cm}$ than in the controls $(\mathrm{p}<0.0001)$ among patients regularly taking PPIs, but not among those not taking PPIs.

When analyzing the strength of the association between obesity and ESBE development on multivariate logistic regression analysis, RE was an independent risk factor for $\mathrm{ESBE} \geq 1 \mathrm{~cm}$ in both patients who were not taking PPIs $(\mathrm{OR}=3.48,95 \% \mathrm{CI}=1.89-6.41, \mathrm{p}<0.0001)$ and those who were regularly taking PPIs $(\mathrm{OR}=5.67,95 \% \mathrm{CI}=2.17$ $14.86, \mathrm{p}=0.0004$ ) (Table 3). Intriguingly, a large WC was a significant risk factor for $\mathrm{BE} \geq 1 \mathrm{~cm}(\mathrm{OR}=5.09,95 \% \mathrm{CI}=$ 2.04-12.72, $\mathrm{p}=0.0005$ ) only among regular PPI users.

Next, the relationship between $\mathrm{RE}$ and the patient characteristics was investigated in patients not taking PPIs. Male sex $(\mathrm{p}<0.0001)$ and alcohol drinking $(\mathrm{p}=$ 0.049 ) were significantly associated with the development of RE (data not shown), whereas gastric atrophy significantly reduced the development $(p=0.02)$. In keeping with the findings from previous studies in the West $[7,8]$ and Japan $[11,12]$ in which RE was significantly associated with obesity, all adiposity measures in the present study, i.e., BMI, WC, and WHR, were significantly greater in patients with $\mathrm{RE}$ than in those without $(\mathrm{p}<0.0001, \mathrm{p}<0.0001$, and $\mathrm{p}=0.0006$, respectively) (Table 4). Moreover, all obesity indices were associated with $\operatorname{RE}(\mathrm{p}=0.001, \mathrm{p}=0.0003$, and $\mathrm{p}=0.02$, respectively). In the multivariate analyses, however, only male sex, but none of the obesity measures, was a risk factor for RE (Table 5). Among patients taking PPIs, only GERD symptoms were significantly associated with RE development $(\mathrm{p}=0.004$, data not shown).

\section{Discussion}

A recent study in the US reported that high WHR, but not BMI, was associated with a significant increase in the risk of LSBE but not short-segment BE in white men [24]. The present study is the first cross-sectional study

Table 3 Predictors of the development of endoscopically suspected Barrett's esophagus

\begin{tabular}{|c|c|c|c|c|c|c|}
\hline \multicolumn{7}{|c|}{ A. Patients not taking proton pump inhibitors } \\
\hline & \multicolumn{3}{|c|}{ Univariate } & \multicolumn{3}{|c|}{ Multivariate } \\
\hline & OR & $95 \% \mathrm{Cl}$ & $P$ value & OR & $95 \% \mathrm{Cl}$ & $P$ value \\
\hline Male sex & 1.81 & $1.07-3.09$ & 0.03 & 1.61 & $0.94-2.77$ & 0.08 \\
\hline Reflux esophagitis & 3.78 & $2.07-6.91$ & $<0.0001$ & 3.48 & $1.89-6.41$ & $<0.0001$ \\
\hline \multicolumn{7}{|c|}{ B. Patients regularly taking proton pump inhibitors } \\
\hline & \multicolumn{3}{|c|}{ Univariate } & \multicolumn{3}{|c|}{ Multivariate } \\
\hline & OR & $95 \% \mathrm{Cl}$ & $P$ value & OR & $95 \% \mathrm{Cl}$ & $P$ value \\
\hline Reflux esophagitis & 5.67 & $2.17-14.86$ & 0.0004 & 5.67 & $2.17-14.86$ & 0.0004 \\
\hline Large waist circumference * & 5.08 & $2.10-12.33$ & 0.0003 & 5.09 & $2.04-12.72$ & 0.0005 \\
\hline
\end{tabular}

$O R$ odds ratio, $\mathrm{Cl}$ confidence interval.

* Large waist circumference is defined as $\geq 85 \mathrm{~cm}$ for males and $\geq 90 \mathrm{~cm}$ for females. 
Table 4 Relationship between reflux esophagitis and obesity in patients not taking PPIs

\begin{tabular}{|c|c|c|c|}
\hline \multirow[b]{2}{*}{ Adiposity measures } & \multicolumn{2}{|c|}{ Reflux esophagitis } & \multirow[b]{2}{*}{$P$ value } \\
\hline & Positive & Negative & \\
\hline $\mathrm{BMI}, \mathrm{kg} / \mathrm{m}^{2}$ & $23.6 \pm 3.6$ & $22.4 \pm 3.4$ & $<0.0001$ \\
\hline$W C, \mathrm{~cm}$ & $84.5 \pm 10.0$ & $80.8 \pm 10.1$ & $<0.0001$ \\
\hline WHR & $0.90 \pm 0.07$ & $0.87 \pm 0.08$ & 0.0006 \\
\hline
\end{tabular}

PPI proton pump inhibitor, BMI body mass index, WC waist circumference, WHR waist-to-hip ratio.

using prospective endoscopic data collection to evaluate the association between obesity and the risk of ESBE, especially short-segment ESBE, in a Japanese population. The pathognomonic point of this study is that the risk factors for $E S B E \geq 1 \mathrm{~cm}$, excluding ultra-short ESBE for which endoscopic diagnosis is highly unreliable, were investigated separately in subjects taking and those not taking PPIs in order to exclude the possibility of a drug affecting the pathophysiology of BE.

The natural history of GERD, including RE, is incompletely understood because very few well-designed prospective studies and endoscopic studies in general populations have been performed [30]. In the current study, RE was a significant risk factor for ESBE development. In two retrospective studies from Japan, RE was shown to be associated with ESBE $[13,14]$ and also with the progression of ESBE using a multivariate model [13]. Therefore, the present findings support these previous results from Japan. However, these studies unfortunately included ultra-short ESBE. According to the previous reports [14,22,23], PPI administration might heal $\mathrm{RE}$ and induce short $\mathrm{BE}$ to regress. Of 367 patients who were regularly taking PPIs, 33 subjects (9.0\%) showed RE in the present study (data not shown). It has been reported that the proportion of PPI-refractory RE patients is approximately $7-15 \%$ [31], a finding that is consistent with the present result. Furthermore, the incidence of PPI treatment-resistant RE was significantly higher in patients with ESBE $\geq 1 \mathrm{~cm}(34.8 \%)$ than in those with ultra- short $\operatorname{ESBE}(3.4 \%, 3$ of 88$)(\mathrm{p}=0.0001$, data not shown). These results indicate that PPI-refractory RE may be strongly associated with an increasing risk of developing $\mathrm{ESBE} \geq 1 \mathrm{~cm}$.

In the current study, all adiposity measures were significantly associated with RE, whereas obesity was not a risk factor for increased BE. Observational studies from Asia have reported a consistent association between WC or VAT and RE $[32,33]$. Two studies of RE in a Japanese population showed that abdominal obesity may be an important risk factor for RE in males, but not in females $[34,35]$, but another report did not show this association [36], which has led to some controversy about the association between obesity and RE. The present study clearly demonstrated that RE was an independent risk factor for ESBE, while obesity was not a risk factor for RE. Only male sex was an independent risk factor for RE development. As reported previously from Western countries, differences in body fat distribution, rather than simple obesity as measured by the BMI, may cause GERD or BE, with abdominal fat deposition leading to an increase in intra-abdominal pressure and GERD. Corley et al. also noted that WC may predict the risk of $\mathrm{BE}$ or esophageal adenocarcinoma better than BMI [9]. It is also true that there are differences in the demographic distribution of $\mathrm{BE}$ by race and ethnicity [37]. The difference in the association between obesity and $\mathrm{RE}$ or $\mathrm{BE}$ might be explained, at least in part, by ethnic differences in the obesity pattern, especially the pattern of visceral adipose tissue deposition [15]. Intriguingly, in patients who are taking PPIs, large WC was a risk factor for ESBE $\geq 1 \mathrm{~cm}$ but not for ultra-short ESBE (data not shown), although the reason for this finding is unclear. The differences in risk factors between ultra-short and $\mathrm{BE} \geq 1 \mathrm{~cm}$ indicate that the pathophysiologies of these two conditions may be different [38]. One possible mechanism for the development of ESBE $\geq 1 \mathrm{~cm}$ in Japanese subjects may be that visceral obesity as measured by WC is associated with severe esophageal acid

Table 5 Predictors for the development of reflux esophagitis in patients who are not taking PPIs

\begin{tabular}{|c|c|c|c|c|c|c|}
\hline & \multicolumn{3}{|c|}{ Univariate } & \multicolumn{3}{|c|}{ Multivariate } \\
\hline & OR & $95 \% \mathrm{Cl}$ & $P$ value & OR & $95 \% \mathrm{Cl}$ & $P$ value \\
\hline Male sex & 2.57 & $1.68-3.93$ & $<0.0001$ & 2.22 & $1.25-3.92$ & 0.006 \\
\hline Alcohol drinking & 1.47 & $1.01-2.15$ & 0.05 & 1.10 & $0.68-1.80$ & 0.70 \\
\hline Gastric atrophy (Open-type) & 0.54 & $0.31-0.93$ & 0.03 & 0.57 & $0.32-1.03$ & 0.06 \\
\hline $\mathrm{BMI}(25 \leq)$ & 1.95 & $1.31-2.92$ & 0.001 & 1.51 & $0.85-2.70$ & 0.16 \\
\hline$W C *$ & 1.98 & $1.37-2.87$ & 0.0003 & 1.04 & $0.56-1.94$ & 0.89 \\
\hline WHR $* *$ & 1.70 & $1.09-2.66$ & 0.02 & 1.57 & $0.92-2.67$ & 0.10 \\
\hline
\end{tabular}

PPI proton pump inhibitor, OR odds ratio, $C$ confidence interval, $B M I$ body mass index, WC waist circumference, WHR waist-to-hip ratio.

* Large waist circumference is defined as $85 \mathrm{~cm} \leq$ for males and $90 \mathrm{~cm} \leq$ for females.

** Large waist-hip ratio is defined as $\geq 0.9$ for males and $\geq 0.85$ for females. 
exposure that cannot be sufficiently inhibited by PPI treatment alone. Therefore, 24-hour esophageal $\mathrm{pH}$ monitoring will be needed to clarify the mechanism in such patients.

Male sex was not a significant risk factor for ESBE with or without PPIs (OR 1.61, 95\% CI =0.94-2.77, $\mathrm{p}=$ 0.08 ) in this study, although it was associated with an increased risk of RE development. Male sex has been reported to be an important predictive factor for $\mathrm{BE}$ $[10,37]$. Generally, the appropriate WC in females differs from that in males because there is a difference in the preferential accumulation of VAT between females and males $[39,40]$. Thus, the risk factors for BE development may be different between females and males. However, no association between obesity and RE or ESBE was found in either females or males in the present study (data not shown). Further investigation may be required using a larger series of samples to determine the association between gender and $\mathrm{BE}$.

There was no significant difference in the prevalence of ESBE, including ultra-short ESBE, between patients taking PPIs (30.2\%, 111 of 367) and those not taking PPIs $(30.8 \%, 374$ of 1214). The prevalence rates of endoscopically suspected LSBE were only $1.1 \%$ and $0.2 \%$ in patients taking PPIs and those not taking PPIs, respectively; therefore, the remaining cases were mostly shortsegment ESBE, especially ultra-short ESBE $<1 \mathrm{~cm}$. These findings are consistent with reports from Japan and Asia, in which SSBE was shown to be more common and LSBE more rare than in Western countries [41,42]. It remains unclear why the prevalence of LSBE is different between Japan and the West. Some possible reasons for this difference include differences in genetic susceptibility, genetic polymorphisms, diet or other clinical/ nutritional factors, and environmental influences (socioeconomic status) [43], along with differences in the definition of the BE and GEJ.

The frequency of SIM increased with longer $\mathrm{BE}$, a finding that is consistent with recent reports [44,45]. In our study, biopsy sampling was not done based on the Seattle biopsy protocol, which is a widely accepted method for performing surveillance biopsies [46], and this omission presumably increased the chance of bias inclusion. However, SIM was detected in 38.8\% (19 of 49) of patients with $E S B E \geq 1 \mathrm{~cm}$ who were not taking PPIs, even in those with ultra-short BE (20.2\%, 23 of $114)$, and this prevalence was higher compared to the finding of Westerhoff et al. [44]. It may be problematic to distinguish metaplasia of the gastric cardia from metaplasia of the $\mathrm{BE}$ and GEJ [10]. We previously reported that SIM obtained from SSBE, mostly ultrashort BE, was distinct from metaplasia in the cardia and the antrum from a practical molecular pathology standpoint [47]. More recently, it was reported that palisade vessels are a specific, original, and useful histologic marker of tissue originating from the esophagus [48], thus supporting the Japanese criteria in which the distal end of the esophageal palisade vessels is considered the GEJ. Taking the findings of these reports into consideration, we believe that ESBE with palisade vessels as investigated in the present study should actually be diagnosed as BE irrespective of the presence or absence of SIM based on the Japanese [49] or British criteria [50].

The present study had several potential limitations. A possible weakness is that only ESBE without histological confirmation of SIM was evaluated, in contrast with the American criteria [21]. Although we examined the effect of obesity on the risk of BE with SIM, there was no significant association between them because of the limited number of cases of BE $\geq 1 \mathrm{~cm}$ with SIM $(n=19)$. Further study will be needed to accurately clarify this association in a Japanese population as well as in the West. Second, this study was a hospital/clinic-based study, so the pooled data might not represent the general population. In addition, the sample size was relatively small. Third, it was not established whether any of the endoscopic BE patients had a hiatus hernia, which is thought to be a risk factor of $\mathrm{BE}$ development, as shown previously $[14,15,20]$. Fourth, H. pylori infection, which appears to have an inverse association with $\mathrm{BE}$, was not evaluated $[40,51]$. However, the present study showed that gastric atrophy, which is caused by $H$. pylori infection, was not related to $\mathrm{BE}$ development, a finding that is consistent with the previous study [13]. Additionally, we did not analyze the administration of nonsteroidal antiinflammatory drugs, including aspirin, which have been significantly associated with a risk of BE [52].

\section{Conclusions}

In conclusion, simple and visceral obesity were not risk factors for ESBE in the present study. In fact, RE was the only one of the parameters studied that was a significant risk factor for ESBE independent of obesity. Interestingly, PPI-refractory RE and large WC in regular PPI users were strongly associated with increasing risk of $E S B E \geq 1 \mathrm{~cm}$. Further studies with a larger sample size will be needed to clarify the reason for this lack of association between obesity and ESBE in the Japanese population.

\section{Abbreviations}

BE: Barrett's esophagus; ESBE: Endoscopically suspected BE; BMI: Body mass index; WC: Waist circumference; WHR: Waist-to-hip ratio; VAT: Visceral adipose tissue; PPI: Proton pump inhibitor; RE: Reflux esophagitis; GERD: Gastroesophageal reflux disease; GEJ: Gastroesophageal junction; SIM: Specialized intestinal metaplasia; OR: Odds ratio; Cl: Confidence interval.

\section{Competing interests}

The authors declare that they have no competing interests. 


\section{Authors' contributions}

JW provided major input into the conceptual development of the study, analyzed the dataset, wrote the manuscript and supervised all investigations. All authors performed esophagogastroduodenoscopy according to our endoscopy protocol and measured adiposity measures in the patients. NK input all the data to a database. JW and HM had full access to all of the data (including statistical reports and tables) in the study and take responsibility for the integrity of the data and the accuracy of the data analysis. All authors read and approved the final manuscript.

\section{Acknowledgement}

This work was supported in part by a grant from the Ministry of Education, Culture, Sports, Science and Technology of Japan through a Grant-in-Aid for Scientific Research (C) 2010-2012 (No. 10010730).

Received: 17 March 2013 Accepted: 20 September 2013 Published: 26 September 2013

\section{References}

1. Falk GW: Barrett's esophagus. Gastroenterology 2002, 122:1569-1591.

2. Jankowski JA, Harrison RF, Perry I, Balkwill F, Tselepis C: Barrett's metaplasia. Lancet 2000, 356:2079-2085.

3. Sampliner RE: Updated guidelines for the diagnosis, surveillance, and therapy of Barrett's esophagus. Am J Gastroenterol 2002, 97:1888-1895.

4. Sampliner RE: Epidemiology, pathophysiology, and treatment of Barrett's esophagus: reducing mortality from esophageal adenocarcinoma. Med Clin North Am 2005, 89:293-312.

5. El-Serag HG: Time trends of gastroesophageal reflux disease: a systematic review. Clin Gastroenterol Hepatol 2007, 5:17-26.

6. Fujiwara Y, Arakawa T: Epidemiology and clinical characteristics of GERD in the Japanese population. J Gastroenterol 2009, 44:518-534.

7. El-Serag H: The association between obesity and GERD: a review of the epidemiological evidence. Dig Dis Sci 2008, 53:2307-2312

8. Hampel H, Abraham NS, El-Serag HB: Meta-analysis: obesity and the risk for gastroesophageal reflux disease and its complications. Ann Intern Med 2005, 143:199-211.

9. Corley DA, Kubo A, Levin TR, Block G, Habel L, Zhao W, Leighton P, Quesenberry C, Rumore GJ, Buffler PA: Abdominal obesity and body mass index as risk factors for Barrett's esophagus. Gastroenterology 2007, 133:34-41.

10. Edelstein ZR, Farrow DC, Bronner MP, Rosen SN, Vaughan TL: Central adiposity and risk of Barrett's esophagus. Gastroenterology 2007, 133:403-411.

11. Moki F, Kusano M, Mizuide M, Shimoyama Y, Kawamura O, Takagi H, Imai T, Mori M: Association between reflux oesophagitis and features of the metabolic syndrome in Japan. Aliment Pharmacol Ther 2007, 26:1069-1075.

12. Sakaguchi M, Oka H, Hashimoto T, Asakuma Y, Takao M, Gon G, Yamamoto M, Tsuji Y, Yamamoto N, Shimada M, Lee K, Ashida K: Obesity as a risk factor for GERD in Japan. J Gastroenterol 2008, 43:57-62.

13. Akiyama $T$, Inamori $M$, Akimoto $K$, lida $H$, Mawatari $H$, Endo $H$, Ikeda $T$, Nozaki Y, Yoneda K, Sakamoto Y, Fujita K, Yoneda M, Takahashi H, Hirokawa S, Goto A, Abe Y, Kirikoshi H, Kobayashi N, Kubota K, Saito S, Nakajima A: Risk factors for the progression of endoscopic Barrett's epithelium in Japan: a multivariate analysis based on the Prague C \& M Criteria. Dig Dis Sci 2009, 54:1702-1707

14. Okita K, Amano Y, Takahashi Y, Mishima Y, Moriyama N, Ishimura N, Ishihara S, Kinoshita Y: Barrett's esophagus in Japanese patients: its prevalence, form, and elongation. J Gastroenterol 2008, 43:928-934.

15. Akiyama T, Yoneda $\mathrm{M}$, Inamori $\mathrm{M}$, lida $\mathrm{H}$, Endo $\mathrm{H}$, Hosono $\mathrm{K}$, Yoneda $\mathrm{K}$, Fujita K, Koide T, Tokoro C, Takahashi H, Goto A, Abe Y, Kirikoshi H, Kobayashi N, Kubota K, Saito S, Nakajima A: Visceral obesity and the risk of Barrett's esophagus in Japanese patients with non-alcoholic fatty liver disease. BMC Gastroenterol 2009, 9:56.

16. Sharma P, Dent J, Armstrong D, Bergman JJ, Gossner L, Hoshihara Y, Jankowski JA, Junghard O, Lundell L, Tytgat GN, Vieth M: The development and validation of an endoscopic grading system for Barrett's esophagus: the Prague C \& M criteria. Gastroenterology 2006, 131:1392-1399.

17. Miwa H, Yokoyama T, Hori K, Sakagami T, Oshima T, Tomita T, Fujiwara Y, Saita H, Itou T, Ogawa H, Nakamura Y, Kishi K, Murayama Y, Hayashi E, Kobayashi K, Tano N, Matsushita K, Kawamoto H, Sawada Y, Ohkawa A, Arai E, Nagao K, Hamamoto N, Sugiyasu Y, Sugimoto K, Hara H, Tanimura M, Honda Y, Isozaki K, Noda S, Kubota S, Himeno S: Interobserver agreement in endoscopic evaluation of reflux esophagitis using a modified Los Angeles classification incorporating grades $\mathrm{N}$ and $\mathrm{M}$ : a validation study in a cohort of Japanese endoscopists. Dis Esophagus 2008, 21:355-363.

18. Lee YC, Cook MB, Bhatia S, Chow WH, El-Omar EM, Goto H, Lin JT, Li YQ Rhee PL, Sharma P, Sung JJ, Wong JY, Wu JC, Ho KY, Asian Barrett's Consortium: Interobserver reliability in the endoscopic diagnosis and grading of Barrett's esophagus: an Asian multinational study. Endoscopy 2010, 42:699-704.

19. Amano Y, Ishimura N, Furuta K, Takahashi Y, Chinuki D, Mishima Y, Moriyama I, Fukuhara H, Ishihara S, Adachi K, Kinoshita Y: Which landmark results in a more consistent diagnosis of Barrett's esophagus, the gastric folds or the palisade vessels? Gastrointest Endosc 2006, 64:206-211.

20. Kinjo T, Kusano C, Oda I, Gotoda T: Prague C\&M and Japanese criteria: shades of Barrett's esophagus endoscopic diagnosis. J Gastroenterol 2010, 45:1039-1044

21. Vakil N, van Zanten SV, Kahrilas P, Dent J, Jones R, Global Consensus Group: The Montreal definition and classification of gastroesophageal reflux disease: a global evidence-based consensus. Am J Gastroenterol 2006, 101:1900-1920.

22. Horwhat JD, Baroni D, Maydonovitch C, Osgard E, Ormseth E, RuedaPedraza E, Lee HJ, Hirota WK, Wong RK: Normalization of intestinal metaplasia in the esophagus and esophagogastric junction: incidence and clinical data. Am J Gastroenterol 2007, 102:497-506.

23. Peters FT, Ganesh S, Kuipers El, Sluiter WJ, Klinkenberg-Knol EC, Lamers CB, Kleibeuker $\mathrm{JH}$ : Endoscopic regression of Barrett's oesophagus during omeprazole treatment; a randomised double blind study. Gut 1999, 45:489-494.

24. Kramer JR, Fischbach LA, Richardson P, Alsarraj A, Fitzgerald S, Shaib Y, Abraham NS, Velez M, Cole R, Anand B, Verstovsek G, Rugge M, Parente P, Graham DY, El-Serag HB: Waist-to-hip ratio, but not body mass index, is associated with an increased risk of Barrett's esophagus in white men. Clin Gastroenterol Hepatol 2013, 11:373-381.

25. Kimura K, Takemoto T: An endoscopic recognition of the atrophic border and its significance in chronic gastritis. Endoscopy 1969, 3:87-97.

26. Lundell LR, Dent J, Bennett JR, Blum AL, Armstrong D, Galmiche JP, Johnson F, Hongo M, Richter JE, Spechler SJ, Tytgat GN, Wallin L: Endoscopic assessment of oesophagitis: clinical and functional correlates and further validation of the Los Angeles classification. Gut 1999, 45:172-180.

27. The Examination Committee for Criteria of Metabolic Syndrome in Japan: Definition and diagnosis criteria of metabolic syndrome. J Jpn Soc Intern Med 2005, 94:794-809 (in Japanese).

28. Oda E, Watanabe K: Japanese criteria of metabolic syndrome. Circ J 2006, 70:364.

29. Ilanne-Parikka P, Eriksson JG, Lindström J, Hämäläinen $H$, KeinänenKiukaanniemi S, Laakso M, Louheranta A, Mannelin M, Rastas M, Salminen V, Aunola S, Sundvall J, Valle T, Lahtela J, Valle T, Lahtela J, Uusitupa M, Tuomilehto J, Finnish Diabetes Prevention Study Group: Prevalence of the metabolic syndrome and its components: findings from a Finnish general population sample and the diabetes prevention study cohort. Diabetes Care 2004, 27:2135-2140.

30. Fullard M, Kang JY, Neild P, Poullis A, Maxwell JD: Systematic review: does gastrooesophageal reflux disease progress? Aliment Pharmacol Ther 2006, 24:33-45.

31. Fass R, Shapiro M, Dekel R, Sewell J: Systematic review: proton-pump inhibitor failure in gastro-oesophageal reflux disease-where next? Aliment Pharmacol Ther 2005, 22:79-94.

32. Chung SJ, Kim D, Park MJ, Kim YS, Kim JS, Jung HC, Song IS: Metabolic syndrome and visceral obesity as risk factors for reflux oesophagitis: a cross-sectional case-control study of 7078 Koreans undergoing health check-ups. Gut 2008, 57:1360-1365.

33. Nam SY, Choi IJ, Ryu KH, Park BJ, Kim HB, Nam BH: Abdominal visceral adipose tissue volume is associated with increased risk of erosive esophagitis in men and women. Gastroenterology 2010, 139:1902-1911.

34. Yasuhara H, Miyake Y, Toyokawa T, Matsumoto K, Takahara M, Imada T, Yagi S, Miyatake H, Nakatsu M, Ando M, Hirohata M: Large waist circumference is a risk factor for reflux esophagitis in Japanese males. Digestion 2010, 81:181-187.

35. Kato M, Watabe K, Hamasaki T, Umeda M, Furubayashi A, Kinoshita K, Kishida O, Fujimoto T, Yamada A, Tsukamoto Y, Yamamoto S, Kamada Y, Yoshida Y, Kiso S, Tsutsui S, Kihara S, Hayashi N, Matsuzawa Y: Association of low serum adiponectin levels with erosive esophagitis in men: an analysis of 2405 subjects undergoing physical check-ups. J Gastroenterol 2011, 46:1361-1367. 
36. Gunji T, Sato H, lijima K, Fujibayashi K, Okumura M, Sasabe N, Urabe A, Matsuhashi N: Risk factors for erosive esophagitis: a cross-sectional study of a large number of Japanese males. J Gastroenterol 2011, 46:448-455.

37. Corley DA, Kubo A, Levin TR, Block G, Habel L, Rumore G, Quesenberry C, Buffler P: Race, ethnicity, sex and temporal differences in Barrett's oesophagus diagnosis: a large community-based study, 1994-2006. Gut 2009, 58:182-188.

38. Matsuzaki J, Suzuki H, Asakura K, Saito Y, Hirata K, Takebayashi T, Hibi T: Etiological difference between ultrashort- and short-segment Barrett's esophagus. J Gastroenterol 2011, 46:332-338.

39. Examination Committee of Criteria for 'Obesity disease' in Japan: Japan society for study of obesity: New criteria for 'obesity disease' in Japan. Circ J 2002, 66:987-992.

40. Lean ME, Han TS, Seidell JC: Impairment of health and quality of life in people with large waist circumference. Lancet 1998, 351:853-856.

41. Chang CY, Cook MB, Lee YC, Lin JT, Ando T, Bhatia S, Chow WH, El-Omar EM, Goto H, Li YQ, McColl K, Reddy N, Rhee PL, Sharma P, Sung JJ, Ghoshal U, Wong JY, Wu JC, Zhang J, Ho KY, Asian Barrett's Consortium: Current status of Barrett's esophagus research in Asia. J Gastroenterol Hepatol 2011, 26:240-246.

42. Kawano T, Kouzu T, Ohara S, Kusano M: The prevalence of Barrett's mucosa in the Japanese [Japanese with English abstract]. Gastroenterol Endosc 2005, 47:951-961.

43. Huang Q, Fan X, Agoston AT, Feng A, Yu H, Lauwers G, Zhang L, Odze RD: Comparison of gastro-oesophageal junction carcinomas in Chinese versus American patients. Histopathology 2011, 59:188-197.

44. Westerhoff M, Hovan L, Lee C, Hart J: Effects of dropping the requirement for goblet cells from the diagnosis of Barrett's esophagus. Clin Gastroenterol Hepatol 2012, 10:1232-1236.

45. Balasubramanian G, Singh M, Gupta N, Gaddam S, Giacchino M, Wani SB, Moloney B, Higbee AD, Rastogi A, Bansal A, Sharma P: Prevalence and predictors of columnar lined esophagus in gastroesophageal reflux disease (GERD) patients undergoing upper endoscopy. Am J Gastroenterol 2012, 107:1655-1661.

46. Reid BJ, Blount PL, Feng Z, Levine DS: Optimizing endoscopic biopsy detection of early cancers in Barrett's high-grade dysplasia. Am J Gastroenterol 2000, 95:3089-3096.

47. Watari J, Moriichi K, Tanabe H, Sato R, Fujiya M, Miwa H, Das KM, Kohgo Y: Differences in genetic instability and cellular phenotype among Barrett's, cardiac, and gastric intestinal metaplasia in a Japanese population with Helicobacter pylori. Histopathology 2009, 55:261-269.

48. Aida J, Vieth M, Ell C, May A, Pech O, Hoshihara Y, Kumagai Y, Kawada K, Hishima T, Tateishi Y, Sawabe M, Arai T, Matsuura M, Takubo K: Palisade vessels as a new histologic marker of esophageal origin in ER specimens from columnar-lined esophagus. Am J Surg Pathol 2011, 35:1140-1145.

49. The Japan Esophageal Society: Japanese Classification of Esophageal Cancer, The 10th Edition, Revised Version. Tokyo: Kanehara-shuppan; 2008.

50. Playford RJ: New British Society of Gastroenterology (BSG) guidelines for the diagnosis and management of Barrett's oesophagus. Gut 2006, 55:442.

51. Chang CY, Lee YC, Lee $C T$, Tu CH, Hwang JC, Chiang H, Wu MS, Lin JT: The application of Prague $C$ and $M$ criteria in the diagnosis of Barrett's esophagus in an ethnic Chinese population. Am J Gastroenterol 2009, 104:13-20.

52. Omer ZB, Ananthakrishnan AN, Nattinger KJ, Cole EB, Lin JJ, Kong CY, Hur C: Aspirin protects against Barrett's esophagus in a multivariate logistic regression analysis. Clin Gastroenterol Hepatol 2012, 10:722-727.

doi:10.1186/1471-230X-13-143

Cite this article as: Watari et al:: Association between obesity and Barrett's esophagus in a Japanese population:

a hospital-based, cross-sectional study. BMC Gastroenterology 2013 13:143.

\section{Submit your next manuscript to BioMed Central and take full advantage of:}

- Convenient online submission

- Thorough peer review

- No space constraints or color figure charges

- Immediate publication on acceptance

- Inclusion in PubMed, CAS, Scopus and Google Scholar

- Research which is freely available for redistribution

Submit your manuscript at www.biomedcentral.com/submit 